\title{
Nutritional-Related Predictors of Preterm Birth in North Shewa Hospitals, Central Ethiopia: A Case- Control Study
}

\author{
Berhanu Senbeta Deriba (ID \\ Department of Public Health, Salale \\ University College of Health Sciences, \\ Fitche, Ethiopia
}

Background: Preterm birth (PTB) is the leading cause of newborn death and the second cause of mortality among under-five children. Globally, about 15 million infants are born preterm every year. However, there is a lack of data on the nutritional-related predictors of preterm birth among Ethiopian women. The objective of the study was to identify nutritionalrelated predictors of preterm birth among women who gave birth at North Shewa public Hospitals in central Ethiopia.

Methods: A case-control study was undertaken in public hospitals in the North Shewa zone, central Ethiopia. Interviewer-administered questionnaire was used to gather data, which was then entered into EPI INFO version 7 and then exported to SPSS version 23 for analysis. Data were presented using texts, tables, and proportions. To find predictors of preterm birth, researcher used binary and multiple logistic regression models. The presence of a relationship between PTB and predictor factors was determined using the adjusted odds ratio (AOR), 95\% confidence interval (CI), and p-value $<0.05$.

Results: A total of 161 cases and 322 controls participated in the study making a response rate of $97.6 \%$. Unable to get iron folic acid (IFA) (AOR=2.26, 95\% CI: 1.22, 4.18), not eating additional meals $(\mathrm{AOR}=2.63,95 \% \mathrm{CI}: 1.1,4.62)$, restriction of foods $(\mathrm{AOR}=2.85$, 95\% CI: $1.58,5.12)$, not taking dark green leafy vegetables (DGLV), (AOR=4.46, 95\% CI: $1.72,11.61$ ), and mid upper arm circumference of mother (MUAC) $<23$ centimeters $(\mathrm{AOR}=3.7,95 \% \mathrm{CI}: 2.25,6.11)$ had statistically significant association with premature birth. Conclusion: IFA supplementation, additional meals, food taboo, frequency of DGLV, and MUAC were identified predictors of preterm birth. Encouraging such women to eat additional meals, varieties of diets like vegetables, and fruits during pregnancy, and adhering to culturally appropriate nutrition education to reverse food taboo is compulsory.

Keywords: nutrition, predictors, preterm birth, hospitals, women
Correspondence: Berhanu Senbeta Deriba Tel +251911706358

Email berhanusenbeta55@gmail.com

\section{Background}

Preterm birth is defined by the World Health Organization (WHO) as childbirth happening before 37 weeks gestational age. Every year, fifteen million infants are born prematurely across the world. ${ }^{1}$ Worldwide, the incidence of preterm births is; $9.6 \%$ overall, $7.5 \%$ in industrialized nations, $12.5 \%$ in developing nations, $9.1 \%$ in Asia, $6.2 \%$ in Europe, $10.6 \%$ in North America, and $11.9 \%$ in Africa. Africa and South Asia account for more than $60 \%$ of preterm births in developing nations. ${ }^{2}$ In Ethiopia, the prevalence of preterm birth ranged from $4.4 \%$ to $35 \%{ }^{3,4}$ 
Preterm birth is the leading cause of newborn death and the second leading cause of death in children under the age of five, behind pneumonia. ${ }^{1}$ Due to the initial extended hospital stay, neonatal critical care unit, and ongoing high health care needs for disability, preterm delivery imposes a significant financial cost. ${ }^{5}$

Although worldwide infant mortality rates are decreasing, infant death is becoming a larger share of all deaths among children under the age of five. Preterm birth problems account for $14.1 \%$ of the 7.6 million fatalities in children under the age of five. ${ }^{6}$ Preterm birth complications account for $35 \%$ of neonatal fatalities worldwide, with $44 \%$ of under-five mortality happening during the newborn period. Sub-Saharan Africa is responsible for $39 \%$ of worldwide newborn fatalities, or 31 fatalities per 1000 live births. Almost one million neonates (36\%) died on the day they were delivered, and another one million (37\%) died during the first week after birth. ${ }^{7}$ Preterm delivery has a significant social and economic cost in terms of the unexpected death of a preterm infant, stressful hospital stays, neonatal intensive care expenditures, ongoing health care, and educational demands. Preterm birth is responsible for $75 \%$ of perinatal death and more than half of all long-term morbidity. ${ }^{8}$ Preterm delivery has a substantial social and economic cost in terms of preterm baby death, stressful hospital stays, expense of neonatal intensive care, and ongoing health care and educational demands. ${ }^{9}$ According to estimates, the cost of preterm birth to the United States of America in terms of medical and educational expenditures, as well as lost productivity, was higher than $\$ 26.2$ billion in $2015 .{ }^{1}$ In low-income nations, more than $90 \%$ of extremely preterm newborns die within the first few days of life, but in high-income nations, just $10 \%$ of newborns of similar gestation die. ${ }^{6}$ Some of the risk factors of preterm birth are undernutrition, obesity, anemia, unable to obtain dietary supplements, not consuming vegetables, and low maternal weight, low income. ${ }^{5,10-17}$ Although the fact that eating patterns throughout pregnancy have a critical role in the health of both the mother and the baby and pregnant women have to eat variety of food in addition to taking additional food; nutritional-related predictors of preterm delivery have yet to be examined. ${ }^{18-20}$

Despite the high prevalence of preterm birth in Ethiopia, which causes a variety of morbidities and mortality in mothers and babies, as well as economic losses, no research has been done on nutritional-related predictors of preterm delivery. Furthermore, there is less evidence on nutritional-related determinants of preterm delivery among Ethiopian women, particularly in the research location. Food taboos, additional food consumption, and food frequency were not investigated in relation to premature delivery. Although food taboo is frequent in Ethiopia during pregnancy, its association with adverse birth outcomes such as preterm delivery has not been investigated. As a result, nutritional predictors of preterm delivery were discovered in this study among women who gave birth in public hospitals in central Ethiopia.

\section{Methods}

\section{Study Setting, Design, and Period}

The research was carried out in five public hospitals in the North Shewa zone (Fitche general hospital, Kuyu general hospital, Kundomeskel primary hospital, Muka turi primary hospital, and Shano primary hospital). North Shewa is one of the 20 zones that make up the Oromia regional state, and it is located at the north of Addis Ababa, Ethiopia's capital. According to the North Shewa zone health office report from 2020, it has a total population of 1.6 million, with 49,667 pregnant women. ${ }^{21}$ North Shewa's main city, Fiche, is 114 kilometers from Addis Ababa. ${ }^{22}$ There are five hospitals and 64 health facilities in the zone. There are 2420 health professionals in the North Shewa zone, including 213 midwives. ${ }^{21}$ All of the hospitals in this zone provide community members with maternity services such as family planning, Antenatal Care (ANC), delivery, and postnatal care. From February to June 2020, an institution-based unmatched case-control study was undertaken.

\section{Source and Study Population}

The research's source populations were all women aged 15 to 49 who gave birth in all public hospitals in the North Shewa zone throughout the study period. The study population consisted of all women aged 15 to 49 who gave birth at public hospitals in the North Shewa zone throughout the data collecting period and were included in the study. This study included all moms who gave birth during the data collection period, were willing to participate at any hospital, and whose gestational age was known or approximated from the last menstrual period or by ultrasound. Moms with an unknown gestational age, mothers who had a medically induced termination of pregnancy, women who gave birth before 28 weeks of pregnancy, and those who had stillbirths were all excluded from the study. 
Women who delivered a live infant before 37 weeks of pregnancy were considered cases, whereas mothers who delivered a live infant at or after 37 weeks of pregnancy were considered controls. $^{23}$

\section{Sample Size Determination and Sampling Procedure}

The sample size was calculated using the double population proportion formula and EPI INFO version 7 with the assumptions of a confidence level of $95 \%(Z \alpha / 2=1.96)$, power of $80 \%(Z=0.84)$, and a case-to-control ratio of $1: 2$, where P1 represents the proportion of cases exposed and $\mathrm{P} 2$ represents the proportion of controls exposed. The variable Mid Upper Circumference (MUAC) of mothers with a waist circumference of less than $21 \mathrm{~cm}$ was used as a predictor of preterm delivery in a research done in Ethiopia's Tigray area $(\mathrm{P} 1=19.8 \%, \mathrm{p} 2=80.20$, and $\mathrm{AOR}=2.42$ ). After accounting for a $10 \%$ non-response rate, the final sample size was 165 cases and 330 controls, for a total of 495 research participants. ${ }^{11}$

\section{Sampling Technique}

The study was carried out in five public hospitals in the North Shewa zone. The number of study participants was proportionally assigned to each hospital based on an estimate derived from the average numbers of previous month's delivery services provided, as recorded in each hospital's delivery registration records. In five hospitals, a total of 2185 ladies gave birth from August to December 2019 (the preceding five months). As a result, the sample size for each hospital was calculated by multiplying the average number of pregnant women who delivered in each hospital per five months by the total sample size $(n=495)$, then dividing by the total number of women expected to give birth at five hospitals for five months, as determined by delivery registration of the previous month's delivery services at five hospitals (Participants in the study were chosen by consecutive sampling at each public hospital) (after collecting data from one case, data were also collected from two controls that followed that case).

\section{Data Collection Tool and Procedure}

Interviewer-administered data collection instrument (questionnaire) was developed by reviewing different similar articles. ${ }^{3,4,11,24-28}$ It was prepared in the English language and translated to the local language, Afan Oromo for a better understanding of both data collectors and respondents, and translated back to English version by a language expert. Ten BSC nurses and five BSC midwiferies were selected for data collection and supervision, respectively. Information such as socio-economic, demographic factors, and nutritional-related variables was collected by direct or face-to-face interview using pretested structured questionnaire during the post-delivery hospital stay in the first 24 hours or during discharge from the hospitals. Gestational age was obtained from the Antenatal Care (ANC) record which in turn was estimated from the last menstrual period or early ultrasound (during the first trimester). Information related to newborns was also obtained from the ANC records. Mid upper circumference (MUAC) of the mothers was measured to the nearest $0.1 \mathrm{~cm}$ to determine the nutritional status of the mother by data collectors at the time of data collection using a non-stretchable tape meter. The reliability of the questionnaire was checked with Cronbach's alpha with the value of 0.884 .

\section{Data Quality Assurance}

Three days of training were given for data collectors and supervisors on the objective of the study, contents of the questionnaire, confidentiality, right of respondents, and how to collect data. Pre-tested of the questionnaire was done on $5 \%$ (9 cases and 18 controls) of the sample at Chencho hospital. After the pretest, data collectors and supervisors discussed the questionnaire and modified the tool for any inconsistencies and ambiguity before actual data collection. After data collection, data was entered into the computer twice and checked for consistency.

\section{Operational Definitions}

Cases were mothers who gave live newborns before 37 completed weeks of gestational age. Controls were mothers who gave live newborns at or after 37 completed weeks of gestational age. ${ }^{23}$

Restriction of foods (food taboos) is foods that are strictly prohibited for health, cultural and religious reasons. $^{29}$

\section{Data Processing and Analysis}

Data were checked for completeness and error after collection, then coded, cleaned, and entered by using EPI INFO version 7 and transported to SPSS version 23 for data cleaning and analysis. Texts, tables, graphs, and proportions were used to present data. Binary logistic regression was carried out to identify the association of PTB 
with each nutritional-related predictor of PTB at a p-value of less than $0.25 .^{30}$ Multicollinearity was checked by standard error. Variables with p-value $<0.25$ in bivariate analysis and those that have no collinearity were entered into multiple logistic regressions model to identify determinants of PTB. The goodness of fit model (Hosmer and Lemeshow) was used to select the best multivariate model, and its p-value was 0.860 . Finally, AOR with $95 \% \mathrm{CI}$ and p-value $<0.05$ were considered as statistically significant.

\section{Ethical Consideration}

This research was carried out in line with the Helsinki Declaration. Salale University's Ethical Review Committee approved the study protocol and methodology. Each hospital received an official letter of collaboration. The North Shewa zone health office and all hospitals gave their approval to conduct the study. Written informed permission was acquired from study participants over the age of 18 after they were told of the research's aim and purpose, and written consent was acquired from their parents or guardians if the participants were mothers under the age of 18 years.

\section{Result}

\section{Socio-Demographic-Related}

\section{Characteristic of Study Participants}

A total of 483 women (161 cases and 322 controls) participated in the study making a response rate of $97.6 \%$. The age of study participants ranged 17-38 years for cases and $17-38$ years for controls with the mean age of $27.56 \pm 5.24$ for cases and $26.84 \pm 4.85$ for controls. Seventy (43.5\%) of cases and around one-third, $110(34.2 \%)$ of controls had a family size greater than or equal to five [Table 1].

\section{Nutritional-Related Characteristics of the Study Participants}

More than one-third, 64 (39.8\%) of cases and 38 (11.6\%) of controls had no nutritional counseling during their recent pregnancy. Fifty-one, (31.7\%) of cases and 25 (7.8\%) of controls had meal frequency $\leq 2$ times per day. Seventy-three, $(45.3 \%)$ of cases and 41 (12.7\%) of control did not take iron and folic acid during their recent pregnancies. Fifty-eight, (36\%) of cases and 40 (12.4\%) of controls had a culture that restricts eating food made from butter, fat meat, fruit, and vegetables due to fear of fetal over development and attachment to fetus. Seventy-
Table I Socio-Demographic Characteristics of Women Who Gave Birth in Public Hospitals of North Shewa Zone, from February to June 2020

\begin{tabular}{|c|c|c|}
\hline Variable & Cases: $n=161$ (\%) & Controls=322 (\%) \\
\hline \multicolumn{3}{|l|}{ Residence } \\
\hline Urban & $66(41 \%)$ & $156(48.4 \%)$ \\
\hline Rural & $95(59 \%)$ & $166(51.6 \%)$ \\
\hline \multicolumn{3}{|l|}{ Age groups } \\
\hline $15-24$ & $56(34.8 \%)$ & II 4(35.4\%) \\
\hline $25-34$ & $86(53.4 \%)$ & I78(55.3\%) \\
\hline$\geq 35$ & 19 (11.8\%) & $30(9.3 \%)$ \\
\hline \multicolumn{3}{|l|}{ Ethnicity } \\
\hline Oromo & $110(68.3 \%)$ & $233(72.4 \%)$ \\
\hline Amahara & $47(29.2 \%)$ & 7I(22\%) \\
\hline Others $^{a}$ & $4(2.5 \%)$ & $18(5.6 \%)$ \\
\hline \multicolumn{3}{|l|}{ Family size } \\
\hline$<5$ & $91(56.5 \%)$ & $212(65.8 \%)$ \\
\hline$\geq 5$ & $70(43.5 \%)$ & $110(34.2 \%)$ \\
\hline \multicolumn{3}{|c|}{$\begin{array}{l}\text { Educational status } \\
\text { of mother }\end{array}$} \\
\hline $\begin{array}{l}\text { Have no formal } \\
\text { education }\end{array}$ & $54(33.5 \%)$ & $73(22.7 \%)$ \\
\hline $\begin{array}{l}\text { Have formal } \\
\text { education }\end{array}$ & $107(66.5 \%)$ & $249(77.3 \%)$ \\
\hline \multicolumn{3}{|l|}{ Marital status } \\
\hline Married & I58(98.1\%) & $310(96.3 \%)$ \\
\hline Others $^{\mathrm{b}}$ & $3(1.9 \%)$ & $12(3.7 \%)$ \\
\hline \multicolumn{3}{|c|}{$\begin{array}{l}\text { Educational status } \\
\text { of husband }\end{array}$} \\
\hline $\begin{array}{l}\text { Have no formal } \\
\text { education }\end{array}$ & $50(31.1 \%)$ & $44(13.7 \%)$ \\
\hline $\begin{array}{l}\text { Have formal } \\
\text { education }\end{array}$ & III(68.9\%) & 278(86.3\%) \\
\hline \multicolumn{3}{|l|}{$\begin{array}{l}\text { Occupation of } \\
\text { mother }\end{array}$} \\
\hline Employed & $33(20.5 \%)$ & $106(32.9 \%)$ \\
\hline Unemployed & $128(79.5 \%)$ & $216(67.1 \%)$ \\
\hline \multicolumn{3}{|l|}{$\begin{array}{l}\text { Occupation of } \\
\text { husband }\end{array}$} \\
\hline Employed & $36(22.4 \%)$ & $122(37.9 \%)$ \\
\hline Unemployed & $125(77.3 \%)$ & $200(62.1 \%)$ \\
\hline
\end{tabular}

Note: $\mathrm{a}=$ Tigre and Gurage, $\mathrm{b}=$ single, widowed, and divorce.

one, (44.1\%) of cases and $70(21.7 \%)$ of controls had MUAC $<23$ centimeters. Forty-nine, $(30.4 \%)$ of cases and $49(15.2 \%)$ controls do not eat dark green leafy vegetables at all [Tables 2 and 3]. 
Table 2 Nutritional-Related Characteristics of Women Who Gave Birth in Public Hospitals of North Shewa Zone, from February to June 2020

\begin{tabular}{|c|c|c|}
\hline Variables & Cases: $n=161$ (\%) & Controls=322 (\%) \\
\hline \multicolumn{3}{|l|}{$\begin{array}{l}\text { Have-nutritional } \\
\text { counseling }\end{array}$} \\
\hline Yes & $97(60.2 \%)$ & $284(88.2 \%)$ \\
\hline No & $64(39.8 \%)$ & $38(11.6 \%)$ \\
\hline \multicolumn{3}{|l|}{ Meal frequency } \\
\hline$\leq 2$ times & $51(31.7 \%)$ & $25(7.8 \%)$ \\
\hline 3 times & $68(42.2 \%)$ & $|5|(46.9 \%)$ \\
\hline$\geq 4$ times & $42(26.1 \%)$ & $146(45.3 \%)$ \\
\hline \multirow{3}{*}{\multicolumn{3}{|c|}{$\begin{array}{l}\text { Took iron/folic acid } \\
\text { during current } \\
\text { pregnancy }\end{array}$}} \\
\hline & & \\
\hline & & \\
\hline Yes & $88(54.7 \%)$ & $28 I(87.3 \%)$ \\
\hline No & $73(45.3 \%)$ & $4 I(12.7 \%)$ \\
\hline \multirow{3}{*}{\multicolumn{3}{|c|}{$\begin{array}{l}\text { Took additional food } \\
\text { during current } \\
\text { pregnancy }\end{array}$}} \\
\hline & & \\
\hline & & \\
\hline Yes & $47(29.2 \%)$ & $182(56.5 \%)$ \\
\hline No & II4(70.8\%) & $140(43.5 \%)$ \\
\hline \multirow{4}{*}{\multicolumn{3}{|c|}{$\begin{array}{l}\text { Presence of } \\
\text { forbidden food } \\
\text { during current } \\
\text { pregnancy }\end{array}$}} \\
\hline & & \\
\hline & & \\
\hline & & \\
\hline Yes & $58(36 \%)$ & $40(12.4 \%)$ \\
\hline No & $103(64 \%)$ & $282(87.6 \%)$ \\
\hline \multirow{3}{*}{\multicolumn{3}{|c|}{$\begin{array}{l}\text { Types of restricted } \\
\text { foods during current } \\
\text { pregnancy }\end{array}$}} \\
\hline & & \\
\hline & & \\
\hline Butter and fatty meat & $5(8.6 \%)$ & $9(2.3 \%)$ \\
\hline Fruits and vegetables & $53(91.2 \%)$ & $31(97.7 \%)$ \\
\hline \multicolumn{3}{|l|}{$\begin{array}{l}\text { Reason for } \\
\text { restriction of foods } \\
\text { during current } \\
\text { pregnancy }\end{array}$} \\
\hline $\begin{array}{l}\text { Fear of fetal over } \\
\text { development }\end{array}$ & $48(82.8 \%)$ & $31(97.9 \%)$ \\
\hline $\begin{array}{l}\text { Fear of attachment to } \\
\text { fetus }\end{array}$ & $10(17.2 \%)$ & $9(2.3 \%)$ \\
\hline \multicolumn{3}{|l|}{$\begin{array}{l}\text { Fasting-during } \\
\text { current pregnancy }\end{array}$} \\
\hline Yes & $73(45.3 \%)$ & III(34.5\%) \\
\hline No & $88(54.7 \%)$ & $211(65.5 \%)$ \\
\hline \multicolumn{3}{|l|}{$\begin{array}{l}\text { MUAC of mother in } \\
\text { centimeter }\end{array}$} \\
\hline$<23$ & $71(44.1 \%)$ & $70(21.7 \%)$ \\
\hline$\geq 23$ & $90(65.9 \%)$ & $252(79.3 \%)$ \\
\hline
\end{tabular}

Table 3 Food Frequency of Women, Who Gave Birth at North Shewa Public Hospitals from February to June 2020

\begin{tabular}{|c|c|c|}
\hline Variables & Cases: $n=161$ (\%) & Controls=322 (\%) \\
\hline \multicolumn{3}{|l|}{$\begin{array}{l}\text { Frequency of eating red } \\
\text { meat }\end{array}$} \\
\hline Every other day & $\mathrm{I}(0.6 \%)$ & $4(1.3 \%)$ \\
\hline Once /weak & $8(5 \%)$ & $3 \mathrm{I}(9.6 \%)$ \\
\hline I-2 times/weak & $76(47.2 \%)$ & $189(58.7 \%)$ \\
\hline Do not take & $76(47.2 \%)$ & $98(30.4 \%)$ \\
\hline \multicolumn{3}{|l|}{$\begin{array}{l}\text { Frequency of eating } \\
\text { organ meat }\end{array}$} \\
\hline At least once /weak & $2(1.3 \%)$ & $20(6.2 \%)$ \\
\hline I-2 times/weak & $30(18.6 \%)$ & $66(20.5 \%)$ \\
\hline Do not take & $129(80.1 \%)$ & $236(73.3 \%)$ \\
\hline \multicolumn{3}{|l|}{$\begin{array}{l}\text { Frequency of eating } \\
\text { dark green leafy } \\
\text { vegetables }\end{array}$} \\
\hline Daily & $10(6.2 \%)$ & $45(14 \%)$ \\
\hline Every other day & $33(20.5 \%)$ & $75(23.3 \%)$ \\
\hline Once /weak & $17(10.6 \%)$ & $89(27.6 \%)$ \\
\hline I-2 times/weak & $52(32.3 \%)$ & $64(19.9 \%)$ \\
\hline Do not take & $49(30.4 \%)$ & $49(15.2 \%)$ \\
\hline \multicolumn{3}{|l|}{$\begin{array}{l}\text { Frequency of eating } \\
\text { fruits }\end{array}$} \\
\hline At least every other day & $13(8 \%)$ & $73(22.7 \%)$ \\
\hline Once /weak & $45(28 \%)$ & $118(36.6 \%)$ \\
\hline I-2 times/weak & $46(28.6 \%)$ & $93(28.9 \%)$ \\
\hline Do not take & $57(35.4 \%)$ & $38(11.8 \%)$ \\
\hline \multicolumn{3}{|l|}{$\begin{array}{l}\text { Frequency of eating } \\
\text { eggs }\end{array}$} \\
\hline Daily & $7(4.4 \%)$ & $16(5 \%)$ \\
\hline Every other day & $35(21.7 \%)$ & $90(28 \%)$ \\
\hline Once /weak & $47(29.2 \%)$ & $117(36.3 \%)$ \\
\hline I-2 times/weak & $43(26.7 \%)$ & $68(21.1 \%)$ \\
\hline Do not take & $29(\mid 8 \%)$ & $3 \mathrm{I}(9.6 \%)$ \\
\hline \multicolumn{3}{|l|}{$\begin{array}{l}\text { Frequency of taking } \\
\text { milk and its products }\end{array}$} \\
\hline Daily & $47(29.2 \%)$ & $105(32.6 \%)$ \\
\hline Every other day & $44(27.4 \%)$ & $106(32.9 \%)$ \\
\hline Once /weak & $35(21.7 \%)$ & $63(19.6 \%)$ \\
\hline I-2 times/weak & $20(12.4 \%)$ & $43(13.4 \%)$ \\
\hline Do not take & $15(9.3 \%)$ & $5(1.5 \%)$ \\
\hline \multicolumn{3}{|l|}{$\begin{array}{l}\text { Frequency of eating } \\
\text { foods made from teff }\end{array}$} \\
\hline Daily & $107(66.5 \%)$ & $243(75.5 \%)$ \\
\hline Every other day & $34(21.1 \%)$ & $48(14.9 \%)$ \\
\hline Once /weak & $16(9.9 \%)$ & $14(4.3 \%)$ \\
\hline I-2 times/weak & $3(1.9 \%)$ & II(3.4\%) \\
\hline Do not take & $\mathrm{I}(0.6 \%)$ & $6(1.9 \%)$ \\
\hline
\end{tabular}




\section{Predictors of Preterm Birth}

Bivariate logistic regression was done for each independent variable. Multivariate analysis was done for all variables with p-value $<0.25$ in the bivariate logistic regression after checking for multicollinearity. After adjusting for covariate in multiple logistic regressions analysis, women who did not get IFA supplementation during current pregnancy had 2.26 folds greater odds of preterm birth compared to those who took IFA supplementation. Women who did not eat additional meals during their recent pregnancy had 2.63-fold higher odds of preterm birth compared to those who ate additional meals. The odds of giving preterm birth were 2.85 times greater in women who had food taboo or restricted from eating food made from butter, fat-meat, fruit and vegetables due to fear of the attachment to fetus and fetal overdevelopment than their counterparts during their current pregnancy. Women who took DGLV once in 2 weeks had 2.96 folds higher odds of delivering PTB compared to those who eat DGLV daily. Women who did not eat dark green leafy vegetables totally had 4.46 folds higher odds of PTB than odds of those who eat DGLV daily (DGLV). Women who had MUAC $<23 \mathrm{~cm}$ had higher odds of PTB compared to their counterparts [Table 4].

\section{Discussion}

The chance of giving preterm birth is higher among mothers who did not get the iron and folic acid supplementation, not eating additional meals, presence of food restriction during pregnancy, not taking DGLV, and MUAC of mother $<23 \mathrm{~cm}$.

The result of this study showed that the odds of delivering preterm birth in women who did not get additional meals during their current pregnancies were higher compared to women who got additional meals. It is consistent with study conducted in British and South Ethiopia where any additional dietary supplementation is associated with preterm birth. ${ }^{17,31}$ The reason behind this fact is during pregnancy women need additional meals for themselves, their fetus, and pregnancy outcomes. $^{32}$ If pregnant women do not get additional food, then they can face malnutrition (thinness). Thin women may take a few amounts of vitamins and minerals, low concentration of which causes low blood flow to the uterus and increases maternal infection like PROM which inurns leads to preterm birth. The consumption of a low amount of vitamins and minerals also causes anemia which in turn causes preterm birth. ${ }^{5}$ Pregnant women who do not take enough food during pregnancy are more likely to face health problems like anemia, which in turn leads to PTB. ${ }^{33}$ The finding of this study also signified that maternal nutritional status such that MUAC of mother $<23$ centimeters (malnutrition) was positively associated with preterm birth. It is similar to studies conducted in Asia, Zimbabwe, South Africa, Sidama zone Ethiopia, and another study where mothers with MUAC $<23$ centimeters were more likely to deliver preterm birth. ${ }^{15,23,25,34-36}$ This might be due to as women become undernourished, they are susceptible to chronic diseases that lower their immune status, which in turn leads to activation of maternal-fetal innate immune system, which initiates preterm labor. ${ }^{25}$

The presence of a culture that restricts pregnant women from eating meat, butter, fruit, and vegetables was positively associated with the occurrence of preterm birth. It is in agreement with another study conducted in South Africa where restriction of food during pregnancy was positively associated with preterm birth. ${ }^{33}$ Alarmingly, some of the prohibited foods are from most vital food groups, leaving these pregnant women to limited dietary diversity and susceptible to different nutrient deficiencies, like micronutrients that may lead to malnutrition like anemia during pregnancy. ${ }^{37}$ Moreover, anemia during pregnancy lead to premature birth. ${ }^{38}$

The result of the present finding indicated that statistically significant association of failure to eat dark green leafy vegetables 1-2 times per two weeks and not eating dark green leafy vegetables totally with the occurrence of preterm birth when compared to those who take DGLV daily. It is similar to a study conducted in Shashamane, Ethiopia, where restriction of vegetables was associated with adverse birth outcomes like premature birth. ${ }^{16}$ This is because unable to consume dark green leafy vegetables leads to a deficiency of non-hem iron that causes iron deficiency anemia (vitamin $\mathrm{A}$ and C) that enhances iron absorption ${ }^{39}$ and intake of vegetarian diet was protective for anemia. ${ }^{40,41}$ Thus, unable to eat dark green leafy vegetables causes anemia ${ }^{42}$ which in turn leads to preterm birth.

This study revealed that not taking iron-folic acid supplementation increases the risk of preterm birth. This finding is consistent with another study where iron folic supplementation is positively associated with preterm birth. ${ }^{43}$ The reason behind this fact is women who do not take iron and folic acid are at risk of developing anemia 
Table 4 Nutritional-Related Predictors of Preterm Birth Among Mothers Who Gave Birth in Public Hospitals of the North Shewa Zone, from February to June 2020

\begin{tabular}{|c|c|c|c|c|}
\hline Variables & Cases $=161$ (\%) & Controls=322 (\%) & COR $(95 \% \mathrm{Cl})$ & AOR $(95 \% \mathrm{Cl})$ \\
\hline \multicolumn{5}{|l|}{ Family size } \\
\hline$<5$ & $91(56.5 \%)$ & $212(65.8 \%)$ & 1 & I \\
\hline$\geq 5$ & $70(43.5 \%)$ & $110(34.2 \%)$ & $1.48(1.006,2.18)$. & $\mathrm{I} .3 \mathrm{I}(0.77,2.2 \mathrm{I})$ \\
\hline \multicolumn{5}{|l|}{ Education of mother } \\
\hline Has no formal education & $54(33.5 \%)$ & $73(22.7 \%)$ & $172(1 . \mid 3,2.61)$ & $0.38(0.17,0.87)$ \\
\hline Has formal education & $107(66 . \%)$ & $249(77.3 \%)$ & I & I \\
\hline \multicolumn{5}{|l|}{ Education of husband } \\
\hline Has no formal education & $50(31.1 \%)$ & $44(\mid 3.7 \%)$ & $2.85(I .8,4.6 I)$ & $2.04(0.89,4.64)$ \\
\hline Has formal education & III(68.\%) & $278(86.3 \%)$ & I & I \\
\hline \multicolumn{5}{|l|}{ Occupation of mother } \\
\hline Employed & $33(20.5 \%)$ & $106(32.9 \%)$ & I & 1 \\
\hline Non-employed & $128(79.5 \%)$ & $216(67.1 \%)$ & $1.90(1.22 .2 .98)$ & $0.80(0.421 .97)$ \\
\hline \multicolumn{5}{|l|}{ Occupation of husband } \\
\hline Employed & $36(22.4 \%)$ & $122(37.9 \%)$ & 1 & 1 \\
\hline Non-employed & $125(77 . \%)$ & $200(62.1 \%)$ & $2.12(1,37,3.27)$ & $1.02(0.48,2.20)$ \\
\hline \multicolumn{5}{|l|}{ Nutritional counseling } \\
\hline Yes & $97(60.2 \%)$ & $284(88.2 \%)$ & 1 & 1 \\
\hline No & $64(39.8 \%)$ & $38(11.6 \%)$ & $4.93(3.10,7.83)$ & $\mathrm{I} .6 \mathrm{I}(0.863 .03)$ \\
\hline \multicolumn{5}{|l|}{ IFA supplementation } \\
\hline Yes & $88(54.7 \%)$ & $28 \mathrm{I}(87.3 \%)$ & I & 1 \\
\hline No & $73(45.3 \%)$ & $4 \mathrm{I}(12.7 \%)$ & $5.69(3.62,8.93)$ & $2.26(1.22,4.18) * *$ \\
\hline \multicolumn{5}{|l|}{ Taking addition meals } \\
\hline Yes & $47(29.2 \%)$ & $182(56.5 \%)$ & I & I \\
\hline No & $114(70 \%)$ & $140(43.5 \%)$ & $3.15(2 \cdot 10,4.73)$ & $2.63(1.42,4.89) * *$ \\
\hline \multicolumn{5}{|l|}{ Restriction of food } \\
\hline Yes & $58(36 \%)$ & $40(12.4 \%)$ & $3.97(2.50,6.30)$ & $2.85(1.58,5.12)^{* *}$ \\
\hline No & $88(54.7 \%)$ & $28 I(87.3 \%)$ & I & I \\
\hline \multicolumn{5}{|l|}{ Frequency of taking DGLV } \\
\hline Daily & $10(6.2 \%)$ & $45(14 \%)$ & I & I \\
\hline Every other day & $33(20.5 \%)$ & $75(23.3 \%)$ & $1.98(0.89,4.4)$ & $2.02(0.77,1.5 .26)$ \\
\hline Once /weak & $17(10.6 \%)$ & $89(27.6 \%)$ & $0.86(0.36,2.03)$ & $0.82(0.30,2.23)$ \\
\hline I-2times/weak & $52(32.3 \%)$ & $64(19.9 \%)$ & $3.66(1.68,7.95)$ & $2.96(1.15,7.58) * *$ \\
\hline Do not take & $49(30.4 \%)$ & $49(15.2 \%)$ & $4.5(2.04,9.93)$ & $4.46(I .72, I I .6 I)$ ** \\
\hline \multicolumn{5}{|l|}{ Meal frequency } \\
\hline$\leq 2$ times & $51(31.7 \%)$ & $25(7.8 \%)$ & $7.1(3.94,12.78)$ & $2.47(0.98,2.23)$ \\
\hline 3 times & $68(42.2 \%)$ & $|5|(46.9 \%)$ & $1.57(1.001,2.45)$ & $0.91(0.49,1.70)$ \\
\hline$\geq 4$ times & $42(26.1 \%)$ & $146(45.3 \%)$ & 1 & 1 \\
\hline \multicolumn{5}{|l|}{ MUAC of mother } \\
\hline$<23$ centimeters & $71(44.1 \%)$ & $70(21.7 \%)$ & $4.56(3.03,6.87)$ & $3.7(2.25,6.11)$ ** \\
\hline$\geq 23$ centimeters & $90(65.9 \%)$ & $252(79.3 \%)$ & & 1 \\
\hline
\end{tabular}

Note: $* *=$ statistically significant at $\mathrm{p}$-value $<0.05, \mathrm{l}=$ reference.

Abbreviations: IFA, iron and folic acid; DGLV, dark green leafy vegetables. 
which in turn causes preterm birth. ${ }^{44-46}$ Unable to take folic acid leads to poor organogenesis of infant and causes fetal malformation which in turn causes preterm birth. ${ }^{47}$ As far as we know, our study is the first to find such a significant association between preterm births and restriction of some foods during pregnancy (food taboo), and unable to eat dark green leafy vegetables in Ethiopia.

\section{Strength of the Study}

Obtaining new findings that were not seen in previous research and conducting nutritional-related preterm birth predictions for the first time.

\section{Limitation of the Study}

In terms of nutritional consumption, the study is vulnerable to recall and social desirability bias. Extremely preterm babies (less than 28 weeks) were excluded from the study.

\section{Conclusion}

Not getting IFA supplementation, not being able to acquire additional meals, dietary restriction (food taboo), not eating dark green leafy vegetables throughout pregnancies, and MUAC of mother $23 \mathrm{~cm}$ were all identified as predictors of preterm birth. As a result, it is advised that the regional health bureau promotes health information dissemination through the media on the impact of identified factors of preterm birth and how to address these issues in the context of premature birth. At ANC clinics, health practitioners should deliver behavioral change communication on recognized factors of preterm delivery, as well as IFA supplementation.

\section{Abbreviations}

ANC, antenatal care; $\mathrm{cm}$, centimeter; $\mathrm{CI}$, confidence interval; IFA, iron folic acid; LBW, low birth weight; MUAC, Mid Upper Arm Circumference; PTB, preterm birth; WHO, World Health Organization.

\section{Data Sharing Statement}

The data supporting this work cannot be made publicly available at this time, but it will be made accessible upon reasonable request from the corresponding author.

\section{Ethical Approval and Consent to Participate}

This research was carried out in line with the Helsinki Declaration. Salale University's Ethical Review Committee approved the study protocol and methodology. Each hospital received an official letter of collaboration. The North Shewa zone health office and all hospitals gave their approval to conduct the study. Written informed permission was acquired from study participants over the age of 18 after they were told of the research's aim and purpose, and written consent was acquired from their parents or guardians if the participants were mothers under the age of 18 years.

\section{Acknowledgment}

I would like to thank Salale University for allocating funds to conduct the study. I would also like to express my deepest appreciation to all individuals who supported me during this research work for their crucial contributions. The contribution of the study participants is also greatly appreciated.

\section{Author Contributions}

The author made substantial contributions to conception, design, acquisition of data, or analysis and interpretation of the data. The author took part in drafting the article or revising it critically for important intellectual content; decided to submit it to the current journal. He gave final approval of the version to be published; and decide to be accountable for all aspects of the work.

\section{Funding}

This research work was funded by Salale University. The funders had no role in study design, data collection, analysis, and decision to publish, or preparation of the manuscript.

\section{Disclosure}

There are no conflicts of interest to be declared.

\section{References}

1. Bick D. Born too soon: the global issue of preterm birth. Midwifery. 2012;28(4):401-402. doi:10.1016/j.midw.2012.06.010

2. Beck S, Wojdyla D, Say L, et al. The worldwide incidence of preterm birth: a systematic review of maternal mortality and morbidity. Bull World Health Organ. 2010;88:31-38. doi:10.2471/BLT.08.062554

3. Cherie N, Mebratu A. Adverse Birth Out Comes and Associated Factors among Delivered Mothers in Dessie Referral Hospital. North East Ethiopia. 2018;1-6.

4. Gebreslasie K. Preterm birth and associated factors among mothers who gave birth in Gondar town health institutions. Adv Nursing. 2016;2016.

5. Goldenberg RL, Culhane JF, Iams JD, Romero R. Epidemiology and causes of preterm birth. lancet. 2008;371(9606):75-84. doi:10.1016/ S0140-6736(08)60074-4

6. Black RE, Cousens S, Johnson HL, et al. Global, regional, and national causes of child mortality in 2008: a systematic analysis. lancet. 2010;375(9730):1969-1987. doi:10.1016/S0140-6736(10) $60549-1$ 
7. You DHL, Chen Y, Newby H, et al. Levels and trends in child mortality report, UNInter Agency Group for Child Mortality Estimation. Adv Nursing. . 2014.

8. Hakem H, Abdalla S, Tanyous E. Prevalence And Risk Factors of Preterm Births in the National Ribat University Teaching Hospital, North Sudan, January to April 2012. Obstet Gynaecol Int J. 2015;2 (1):27-29.

9. Bick D. Born too soon: the global issue of preterm birth. Midwifery. 2012;4(28):401-402.

10. Zhang X, Zhou M, Chen L, Hao B, Zhao G. Risk factors for preterm birth: a case-control study in rural area of western China. Int J Clin Exp Med. 2015;8(3):4527.

11. Berhe T, Gebreyesus H, Desta H. Determinants of preterm birth among mothers delivered in Central Zone Hospitals, Tigray, Northern Ethiopia. BMC Res Notes. 2019;12(1):266. doi:10.1186/ s13104-019-4307-z

12. Sifer S, Kedir B, Demisse G. Determinants of preterm birth in neonatal intensive care units at public hospitals in Sidama zone, South East Ethiopia; case control study. J Pediatr Neonatal Care. 2019;9(6):180-186.

13. Adu-Bonsaffoh K, Gyamfi-Bannerman C, Oppong S, Seffah J. Determinants and outcomes of preterm births at a tertiary hospital in Ghana. Placenta. 2019;79:62-67. doi:10.1016/j. placenta.2019.01.007

14. Yeshialem E, Alemnew N, Abera M, Tesfay A. Determinants of Adverse Pregnancy Outcomes among mothers who gave birth from Jan 1-Dec 31/2015 in Jimma University Specialized Hospital, Case control study, 2016. Med Clin Rev. 2017;3(4):22. doi:10.21767/2471299X.1000063

15. Chimhini G, Tshimanga M, Chikwasha V, Mungofa S. Determinants of premature births in two central hospital Harare, Zimbabwe, 2011. Central African J Med. 2013;59(9-12):49-57.

16. Zepro NB. Food taboos and misconceptions among pregnant women of Shashemene District, Ethiopia, 2012. Sci J Public Health. 2015;3 (3):410-416. doi:10.11648/j.sjph.20150303.27

17. Abadiga M, Wakuma B, Oluma A, Fekadu G, Hiko N, Mosisa G. Determinants of preterm birth among women delivered in public hospitals of Western Ethiopia, 2020: unmatched case-control study. PLoS One. 2021;16(1):e0245825. doi:10.1371/journal.pone.0245825

18. Tsakiridis I, Kasapidou E, Dagklis T, et al. Nutrition in Pregnancy: a Comparative Review of Major Guidelines. Obstet Gynecol Surv. 2020;75(11):692-702. doi:10.1097/OGX.0000000000000836

19. Vander Wyst KB, Vercelli ME, O'Brien KO, Cooper EM, Pressman EK, Whisner CM. A social media intervention to improve nutrition knowledge and behaviors of low income, pregnant adolescents and adult women. PLoS One. 2019;14(10):e0223120. doi:10.1371/journal.pone.0223120

20. Soneji S, Beltrán-Sánchez H. Association of special supplemental nutrition program for women, infants, and children with preterm birth and infant mortality. JAMA Network Open. 2019;2(12): e1916722-e. doi:10.1001/jamanetworkopen.2019.16722

21. Office NSzh. Health Management Information Systems January Report, 2020, Fitche, Ethiopia. Fitche, Ethiopia:Office NSzh; 2020. Report No.: 107 Contract No.: 07.

22. Deriba BS, Geleta TA, Beyane RS, Mohammed A, Tesema M, Jemal K. Patient Satisfaction and Associated Factors During COVID-19 Pandemic in North Shoa Health Care Facilities. Patient Prefer Adherence. 2020;14:1923-1934. doi:10.2147/PPA.S276254

23. Blencowe H, Cousens S, Chou D, et al. Born too soon: the global epidemiology of 15 million preterm births. Reprod Health. 2013;10 (1):S2. doi:10.1186/1742-4755-10-S1-S2

24. Mekuriyaw AM, Mihret MS, Yismaw AE. Determinants of Preterm Birth among Women Who Gave Birth in Amhara Region Referral Hospitals, Northern Ethiopia, 2018: institutional Based Case Control Study. Int J Pediatr. 2020;2020:2020. doi:10.1155/2020/1854073
25. Sifer SD, Kedir BS, Demisse GA, Sisay Y. Determinants of preterm birth in neonatal intensive care units at public hospitals in Sidama zone South East Ethiopia case control study. J Pediatrics Neonatal Care. 2019;9(9)

26. Woday A, Muluneh MD, Sherif S. Determinants of preterm birth among mothers who gave birth at public hospitals in the Amhara region, Ethiopia: a case-control study. PLoS One. 2019;14:11. doi:10.1371/journal.pone.0225060

27. Derakhshi B, Esmailnasab N, Ghaderi E, Hemmatpour S. Risk factor of preterm labor in the west of Iran: a case-control study. Iran J Public Health. 2014;43(4):499.

28. CSACE I. Ethiopia Demographic and Health Survey 2016. Addis Ababa, Ethiopia, and Rockville, Maryland, USA: CSA and ICF; 2016.

29. Meyer-Rochow VB. Food taboos: their origins and purposes. J Ethnobiol Ethnomed. 2009;5(1):18. doi:10.1186/1746-4269-5-18

30. Sperandei S. Understanding logistic regression analysis. Biochem Med. 2014;24(1):12-18. doi:10.11613/BM.2014.003

31. Alwan N, Greenwood D, Simpson N, McArdle H, Cade J. The relationship between dietary supplement use in late pregnancy and birth outcomes: a cohort study in British women. BJOG. 2010;117 (7):821-829. doi:10.1111/j.1471-0528.2010.02549.x

32. Marangoni F, Cetin I, Verduci E, et al. Maternal diet and nutrient requirements in pregnancy and breastfeeding. An Italian consensus document. Nutrients. 2016;8(10):629. doi:10.3390/nu8100629

33. Vasilevski V, Carolan-Olah M. Food taboos and nutrition-related pregnancy concerns among Ethiopian women. J Clin Nurs. 2016;25 (19-20):3069-3075. doi:10.1111/jocn.13319

34. Neggers YH. The relationship between preterm birth and underweight in Asian women. Reproductive Toxicol. 2015;56:170-174. doi:10.1016/j.reprotox.2015.03.005

35. Pattinson R, Group P. Saving Babies 2008-2009: Seventh Report on Perinatal Care in South Africa. Pretoria: Tshepesa Press; 2011.

36. Dean SV, Mason EM, Howson CP, Lassi ZS, Imam AM, Bhutta ZA. Born too soon: care before and between pregnancy to prevent preterm births: from evidence to action. Reprod Health. 2013;10(1):1-16. doi:10.1186/1742-4755-10-S1-S3

37. Kariuki LW, Lambert C, Purwestri RC, Maundu P, Biesalski HK. Role of food taboos in energy, macro and micronutrient intake of pregnant women in western Kenya. Nutrition Food Sci. 2017. doi:10.1108/NFS-09-2016-0146

38. Office AtH. Ambo Town Health Office Health Management Information System Annual Report of June 2020. 2020:890-912

39. De Benoist B, Cogswell M, Egli I, McLean E. Worldwide prevalence of anaemia 1993-2005; WHO Global Database of anaemia. $A d v$ Nursing. 2008.

40. Viveki R, Halappanavar A, Viveki P, Halki S, Maled V, Deshpande P. Prevalence of anaemia and its epidemiological determinants in pregnant women. Al Ameen J Med Sci. 2012;5(3):216-223.

41. Melku M, Addis Z, Alem M, Enawgaw B. Prevalence and predictors of maternal anemia during pregnancy in Gondar, Northwest Ethiopia: an institutional based cross-sectional study. Anemia. 2014;2014:2014. doi:10.1155/2014/108593

42. Deriba BS, Bulto GA, Bala ET. Nutritional-Related Predictors of Anemia among Pregnant Women Attending Antenatal Care in Central Ethiopia: an Unmatched Case-Control Study. Biomed Res Int. 2020;2020. doi:10.1155/2020/8824291

43. Mantovani E, Filippini F, Bortolus R, Franchi M. Folic acid supplementation and preterm birth: results from observational studies. Biomed Res Int. 2014;2014. doi:10.1155/2014/481914

44. Organization WH. Guideline: Daily Iron and Folic Acid Supplementation in Pregnant Women. World Health Organization; 2012.

45. Mei Z, Jefferds ME, Namaste S, Suchdev PS, Flores-Ayala RC. Monitoring and surveillance for multiple micronutrient supplements in pregnancy. Matern Child Nutr. 2018;14:e12501. doi:10.1111/ mcn. 12501 
46. Viteri FE, Berger J. Importance of pre-pregnancy and pregnancy iron status: can long-term weekly preventive iron and folic acid supplementation achieve desirable and safe status? Nutr Rev. 2005;63 (suppl_2):S65-S76. doi:10.1301/nr.2005.dec.S65-S76
47. Offiah I, O’Donoghue K, Kenny L. Clinical Risk Factors for Preterm Birth. Preterm Birth-Mother and Child. 1st ed. InTech; 2012:73-94.

\section{Publish your work in this journal}

Pediatric Health, Medicine and Therapeutics is an international, peerreviewed, open access journal publishing original research, reports, editorials, reviews and commentaries. All aspects of health maintenance, preventative measures and disease treatment interventions are addressed within the journal. Practitioners from all disciplines are invited to submit their work as well as healthcare researchers and patient support groups. The manuscript management system is completely online and includes a very quick and fair peer-review system. Visit http://www.dovepress.com/testimonials.php to read real quotes from published authors.

Submit your manuscript here: http://www.dovepress.com/pediatric-health-medicine-and-therapeutics-journal 